\title{
Mística del tabernario: Bosque en llamas'
}

\author{
Raúl Serrano Sánchez \\ Universidad Andina Simón Bolívar, Sede Ecuador \\ raul.serrano@uasb.edu.ec
}

Recibido: 1 -diciembre-2018 / Aceptado: 28 - diciembre-2018

\section{Resumen}

El presente ensayo es un análisis del poemario Mistica del Tabernario del escritor ecuatoriano Raúl Vallejo, que en el año 2017 ganaría el premio literario José Lezama Lima en la Habana. En las siguientes páginas se dará cuenta de la relevancia literaria del libro y, sobre todo, de la relevancia literaria del autor ecuatoriano. Mistica del Tabernario es una obra que homenajea al autor salvadoreño Roque Dalton en el que concentra lenguajes, escenarios, simbología, discursos y estrategias del autor para presentar una obra fundamental en la poesía latinoamericana de los últimos años.

Palabras claves: Raúl Vallejo, Roque Dalton, poesía, literatura

\section{Abstract}

This essay is an analysis of the poetry book Mistica del Tabernario ofEcuadorian writer Raúl Vallejo, who in 2017 would win the literary prize José Lezama Lima in Havana. In the following pages you will realize the literary relevance of the book and, above all, the literary relevance of the Ecuadorian author.

1 Este texto, con algunas variantes, fue el prólogo a la edición local del poemario Mistica del tabernario de Raúl Vallejo, publicado por la Casa de la Cultura Ecuatoriana en 2018 en su Colección Letras Claves. 
Mística del Tabernario is a work that pays homage to the Salvadoran author Roque Dalton in which he concentrates languages, scenarios, symbology, speeches and strategies of the author to present a fundamental work in Latin American poetry in recent years.

Keywords: Raúl Vallejo, Roque Dalton, poetry, literature 
El lenguaje de un poeta es un lenguaje historizado, una relación. E. Montale, "Intenciones (Entrevista imaginaria)"

E n 2015 Raúl Vallejo lanzó en Colombia el poemario Mística del tabernario, ${ }^{2}$ texto que en 2017 mereciera el premio latinoamericano José Lezama Lima otorgado por Casa de las Américas de Cuba; institución que en ese mismo año puso a circular una cuidada edición de este título que es una summa de libros, por tanto un tejido de voces que dan cuenta de una diversidad de lenguajes, de situaciones y estrategias escriturarias que convierten a este texto en una especie de perfomance en la que conviven una pluralidad de discursos así como de actos o perspectivas que se ofrecen al lector/a como un mapa de aquellos lugares secretos y resquebrajados, de esas tabernas de las que en su momento diera cuenta el malogrado Roque Dalton, a quien Vallejo celebra y homenajea en estas páginas de una manera no solo lúcida sino que muy sentida, por tanto legítima; si entendemos como tal la posibilidad de no desvirtuar lo que implica un homenaje a quien sin duda es un referente vital del canon de la poesía latinoamericana de las últimas décadas del siglo XX.

Como en un juego de azar, como suele ser en todo buen juego, este libro se propone a los lectores y lectoras como una estructura abierta, dado que se puede acceder a él sin necesidad de seguir el trazado sugerido por el autor. Cada pieza se integra al mecanismo general sin dejar de tener autonomía, lo que dota al conjunto de una dinámica que resulta seductora por su capacidad de mantener una suerte de música interna, oculta, que no decae en ningún momento. Por ejemplo, si consideramos la primera parte (la que abre este concierto polifónico) "Taberna de la cofradía de Chapinero Bajo", que tiene como subtítulo: "(Conversatorio escénico de la postmodernidad)" (pp. 21-79), ${ }^{3}$ podremos constatar que como parte de las estrategias escriturarias está la convocatoria del sujeto lírico de varios escribas: "Poeta indignado", "Homo libidinosus", "Poeta manteño-huacavilca", "Cronista poscolonial", "Antipoetucho", "Vate memorioso y criticón literario". Entre estos se intercala "Monólogo para actriz invitada", otro homenaje de Vallejo a la siempre vital y conmovedora actriz Marilyn Monroe. Voces de escribas, cada quien con su peculiaridad, que se van alternando para, precisamente, dar cuenta desde la idea de lo conversacional, de los camaleónicos escenarios del momento histórico y político que el sujeto lírico construye y deconstruye en cada uno de los textos que integran este segmento del concierto, que por cierto es el más extenso del libro, y que por sí solo es uno de los cantos más desacralizadores que se han formulado en la lírica ecuatoriana contem-

2 Mistica del tabernario (Bogotá: Casa de Libros Editores, Colección Los Torreones, 2015). Esta edición ya incluye los textos de presentación de Roberto Fernández Retamar y J. Mario Arbeláez.

3 Todas las citas corresponden a la segunda edición, La Habana, 2017. 
poránea respecto a un periodo como al que el autor le ha tocado enfrentar desde varias experiencias vitales; un periodo que da cuenta de las últimas décadas del siglo XX y lo que va del XXI. Este libro se agrega y da cuenta del trabajo sostenido que en el ámbito de la poesía Vallejo viene desarrollando desde que en 2003 lanzó Cánticos para Ariana, en 2007 Crónica del mestizo y en 2008 Missa solemnis.

\section{Macondo y otros lugares}

El hecho de haber definido un foco de poetización como es Chapinero Bajo, quizás una especie de Macondo y Santa María de la postmodernidad, un lugar que no es mítico, sino que el poeta se ha propuesto refundar desde el descrédito de la desmitificación; escenario que le permite levantar todo un mapa respecto a situaciones que han sido tomadas o expropiadas de la cotidianeidad de ese flaneeur del que Walter Benjamín siempre reivindicó, desde Baudelaire, su capacidad para desmontar lo que el ojo de los citadinos (fantasmas con historia privada), son capaces de ir registrando como parte de un ejercicio en el que se conjugan de manera vital y conmovedora lo que tiene de cronista involuntario, pero también de un extranjero que no quiere reconocerse como tal en ese espejo empańado de una realidad que solo el poema, la escritura, hacen palpable o habitable.

Chapinero Bajo no es cualquier lugar, pero es todo lugar que surge desde la memoria de ese "Poeta indignado" que renuncia a ocultar o negarse a la posibilidad de echar a rodar su bolo de lodo suburbano, porque todo lo que le indigna es parte de unas situaciones que la fauna humana ha inventado con tal de legitimar -ya sea desde el poder o la displicencia- para obviar lo que es materia de muchas y múltiples indagaciones. Un sujeto lírico que pone en cuestionamiento el rol de la poesía y del poeta en los tiempos postmodernos: "La poesía es un arma descargada de mundo: poetas suicidas/ solo miran para dentro de sí, la vida se reduce a la letra/ inútil, la única calle que transitamos nos conduce a un final muerto" (p. 23).

La institución poeta y esa arma que es la poesía, a lo largo de esta sección, es seriamente puesta bajo sospecha. Pues, la pregunta con la que Vallejo nos encara, es la misma que en su hora se hicieron los románticos, los vanguardistas y Sartre: ¿para qué sirve la poesía en medio de este valle trensado de tantas violencias, ofensas y puntapiés? Pues, sucede que las respuestas están en algún rincón de los huesos húmeros de los lectores y lectoras, quienes avanzan en este bosque de signos y tatuajes verbales sin querer hacer pausas. Porque sucede que la voz del "Homo libidinosus", nos pone al borde de los estallidos del cuerpo, de los encuentros y desencuentros de los amantes. Unos amantes que, ya en clave postmoderna, han roto con muchas trabas, prejuicios y condenas; pues el motivo y los asuntos de los que nos participa el sujeto lírico en los textos de este bloque, son los de aquellos que desde el ejercicio de su deseo y libertad van más allá de lo que antes eran rémoras impuestas por las fronteras del género. Los amantes que se celebran y celebran estos momentos están ebrios de "virtud y poesía" como reza el verso de Baudelaire; todos son capaces de 
convertir las limitaciones en sustancia, materia de una dicha que la aventura causal o la casualidad de cualquier encuentro es parte de esa fugacidad de la que tanto hablan los poemas de los modernistas; porque sin duda, la eternidad, en una de sus formas más visibles se esculpe en esa condición de lo que siempre está en fuga, ya sea el deseo o lo que el amor suele buscar con tanteos de ciego: "La líbido es un taco de dinamita con la mecha corta/ y no hace distingos de ninguna especie. Esa varona/ ostenta en su cuerpo la mano artística de un cirujano" (p. 32).

\section{Díctico de nombres}

En torno a los homenajes y las celebraciones, las figuras del poeta Dalton y la admirable y lúcida Marilyn Monroe, descuellan por todo lo que su leyenda, antes que su biografía, ha llegado a construir como parte de las mitologías de las que se ha nutrido la cultura de la posmodernidad en América Latina y los Estados Unidos. Dos iconos de dos tiempos que se contraponen, pero que a la vez son convergentes y complementarios. Si bien Marilyn participa de lo que es la cultura del espectáculo y la banalidad de la sociedad capitalista, de las diversas trampas y seducciones, así como máscaras, pues ella es una especie de mártir, de cuerpo escarnecido por parte de un orden en el que se pretendía convertir a la rubia en el modelo de la mujer del "sueño americano", siempre y cuando nunca cuestione ni ponga en entredicho lo mucho que de monstruoso tenía y tiene ese sueńo. En la otra orilla, está el "pobrecito poeta" que era Dalton, un intelectual centroamericano que hizo de su estética, como lo sugerían los vanguardistas de la década del 20 y 30 (el peruano César Vallejo y el chileno Pablo de Rokha, entre otros) en América Latina y Europa, su ética, que se traduce en acciones y posturas que hoy los poetas de la posmodernidad miran con reticencia o un camuflado desdén.

El texto dedicado a Dalton, no solo que es intenso en sus partes y en su todo, sino que conmueve por la legitimad a la hora del discurso que en ningún momento llega al cartel ni se arriesga en lo obvio. Quizás este texto (pp. 36-37) sea uno de los tributo más lúcidos y elocuentes (en el mejor sentido del término) que se haya tributado al autor de Taberna y otros lugares (1969). Aquel libro emblemático que desde su aparición -iparadojas de la literatura!- no ha dejado de influir o al menos de incomodar a quienes hoy prefieren una poesía nada comprometedora en su diálogo con los traumas y fantasmas de la historia. El homenaje de Raúl Vallejo es legítimo porque el texto se funda en una fuerza que proviene desde lo que es la orquestación armoniosa y acertada entre lo vivido y lo poetizado. Sabemos hoy en día lo que sucedió con el famoso sumario (10 de mayo de 1975) que ciertos militantes (como en todo, tenían sus ocultos intereses) fraguaron contra Dalton, valiéndose de acusaciones que han sido debidamente desmentidas y desnudadas como infamias y calumnias que terminaron por estallar en las manos y en el rostro de los acusadores. Esta reconstrucción de Vallejo, es una especie de elegía que termina por hacerle justicia a Dalton, el hombre de acción, y a su palabra poética 
que el tiempo se ha encargado de convertir en lo que sus inquisidores creyeron nunca llegaría a ser: "metáfora viva", como diría Paul Ricoeur, al aludir a aquella palabra que es capaz de trascender todas las formas de bloqueo y olvido. Como bien expresa el verso que cierra este hermoso y estremecedor canto: "La poesía fue fusilada junto con la fragilidad de tu cuerpo" (p. 36).

Lo cierto es que ese fusilamiento aún resuena al igual que las balas que acabaron con un místico de la posmodernidad como Lennon. Resuenan porque para el poder y sus fantoches, sean del lado que sean, la poesía y los poetas siempre son un asunto con el que nunca, a buena hora, van a terminar entendiéndose bien.

El otro homenaje del que nos participa Vallejo, es el que consagra a la protagonista de obras maestras del cine (baste citar Con faldas y a lo loco -1959- o Los inadaptados-1961-). Cuatro textos en los que se reconstruye, desde los escombros de la biografía de Marilyn, su leyenda. Quizás estos momentos sean los verdaderos; tal vez esta sea la ficción que Marilyn siempre quiso vivir, pero que la gris realidad de su vida le arrebató. De pronto cada uno de estos cortos de su historia no hacen sino ponernos cerca, muy cerca de esa criatura que Truman Capote definió como "adorable", porque sin duda que lo era y lo es.

Probablemente, para aquel lector o lectora que no esté tan informada de algunos episodios de la vida truculenta y siempre desconcertante de Marilyn, entrar a estos textos les permitirá cargarse de preguntas y de una furia que los convertirá en culpables de saber cómo una sociedad excluyente, hipócrita y machista, fue capaz de arrastrar hasta los quintos infierno a una criatura que, paradójicamente, le dio a ese infierno del sueño americano, un grado de ternura, de sensibilidad, cierto hálito de humanidad que nunca le fue retribuido:

Soy una muñeca moribunda, cebada de cocaína, muñeca de nembutal bajo las oscuras luces de Hollywood (p. 62).

Vale subrayar que este cuarteto dedicado a la diosa, dialoga a plenitud con la hermosa nouvelle de Vallejo, Marilyn en el Caribe (2015). Es más, diría que estos poemas se convierten en un paratexto. Quienes se sumerjan en las aguas de la novela, al contraponer o al poner en paralelo los poemas, podrán enriquecer el juego de sentidos en el que navega la historia de la actriz en esa Habana en donde resucita en todo su esplendor y misterio dentro de una trama con aires de filme de espionaje de la Guerra Fría.

Lo lúdico de esta sección de apertura de Mistica del tabernario, se hace evidente en el cierre, así como en el empleo de una voz que se cuela en algunos textos y que corresponde al "Tuiteropoeta@tabernario"; una especie de conciencia crítica que lleva los apuntes telegráficos a pie de página, y que por general son un contra-discurso. El escriba de este texto es el "Poeta manteño-huancavilca" (alusión irónica a la condición identitaria del autor que nació en el puerto de Manta pero que se crio en Guayaquil), quien tiene la tarea de asumir la despedida de lo que es el universo 
mítico de Chapinero Bajo (esa conjunción entre cielo e infierno). Se trata, también, de un inventario de los afectos, de nombres y personas; lugares, escenarios que forman parte, sustancia matérica de la escritura del poeta:

Digo adiós con la piadosa vergüenza de ocuparme de estos versos y de compartir con ustedes mi orfandad redimida por la poesía (p. 79).

\section{Escenas de lo virtual}

Un segundo momento de Mistica del tabernario es "Escenas en las redes sociales" (pp. 83-97).

Crónica del sujeto que es parte del paisaje urbano postmoderno en esa doble condición de fantasma y desterrado no solo de su propia comarca, sino de su condición de sujeto, esto es de alguien que antes era parte de un recodo urbano más humano, menos hostil, porque ahora "Somos seres conectados por cables invisibles/ que nos convierten en islas sobre el asfalto" (p. 84).

No cabe duda, y esta escena así lo evidencia, que si bien hoy el entramado de las tecnologías nos tiene más "conectados", lo cierto es que al mismo tiempo estamos, en términos humanos, cada vez más al margen. Aquello de lo que el célebre poeta metafísico inglés, John Donne, advirtiera en su hermoso texto: "Ningún hombre es una isla entera por sí mismo", hoy es algo más que una metáfora; sucede que -Vallejo nos participa de esta revelación- el capitalismo del siglo XXI ha logrado, como parte de sus estrategias de vigilar y castigar, que seamos sutilmente islas que cada quien forja a imagen y semejanza. Ahora, las evidencias nos abruman, cada hombre y mujer se van tornando islas automatizadas y posesas por esos seductores objetos tecnológicos, típicos de la pasión y el deseo posmoderno con los que cada quien construye su dicha e infierno privado:

Todos somos navegantes extraviados del ciberespacio porque vivimos como androides con vísceras (p. 90).

Ese extravío de los navegantes llega a ser mucho más dramático y patético con la idea de que lo asumen como Ulises que libran tantos desafíos desde su cómoda y narcótica condición de sedentarios sometidos y maniatados, para quienes Itaca no es un camino ni un reino a donde ir, sino un teclado desde el que su vida y sus sueños se van consumiendo de manera terrorífica:

Yo soy el Ulises del puerto virtual que navega anclado, ser que te da la forma en su teclado de sedentario. (p. 97).

Por su parte, "Procreación de identidades" (pp. 99-133), es un grupo de textos en los que se examina un tema que le es muy caro a Vallejo y que abordó con 
honestidad y hondura en algunos de sus cuentarios, sobre todo en Fiesta de solitarios (1992) y en Huellas de amor eterno (2000). Ese tema alude a la condición del sujeto que desde el territorio y las ambigüedades del cuerpo, en continuo cuestionamiento e interpelación, busca lo que la pasión amorosa le puede otorgar como parte de una libertad en la que lo identitario (la deconstrucción del género) es un desmontaje que nos plantea preguntas como: ¿quién es él o ella a la hora del deseo?, ¿quién es ella o él a la hora en que la carne quiere fusionarse con ese otro/a al que busca como una complementariedad que es ilegítima ante el poder convencional y las instituciones coercitivas que se han construido para normar lo humano, lo demasiado humano.

La fuerza de estos textos arrasa con todo, incluso con esa falsa moralidad o esas limitantes que al deseo y sus diversas formas de realizarse el poder y sus instituciones pretenden bloquear con una legalidad que entra en contradicción con las demandas impostergables de los cuerpos. Aquí los amantes de variado cuńo (Vallejo nos recuerda que la aventura amorosa es plural) son parte de esa vorágine en la que todo es celebración, encuentros y adioses que la escritura ha transformado en cuerpos textuales:

Él, ella, procreación de identidades;

su ser es un estuario en el que desembocan

las almas que se liberan de la vergüenza de sus tumbas (p. 117).

\section{Memoria y tribu}

Otra de las celebraciones presentes en Mistica del tabernario, es la tribu. Aquellas presencias fundamentales en la vida de ese cronista poscolonial al que los "heraldos negros" que trae la parca, lo llevan a expurgar el archivo y el álbum familiar en el que las fotos, los gestos, los rituales que los olores, con las ausencias que funden y reformulan la materia de la memoria, desfilan como elementos de una película que el sujeto lírico mira a espaldas del mundo, en un rapto en el que el poema se torna oración. Ese cántico espiritual del que San Juan de la Cruz aún nos sigue murmurando sus múltiples "espesuras".

Tríptico compuesto por "Padre ¿extraviaste nuestros nombres acaso?" (pp. 147142); "Madre, sé que me nombras desde lo eterno" (pp. 143-151); "Tito de alma liviana, hermano mío, mi lumbre inextinguible" (pp. 153-156). Textos en los que Vallejo intensa y alucinadamente canta, celebra y descifra al padre que es una presencia ausente, a la madre que como esa Penélope que tejía y destejía en el más ruidoso de los silencios y de la soledad fragmentos de su agonía y resurrección, nunca deja de repartir el pan nuestro de cada día. Luego está el hermano mayor, demiurgo que trastocó la vida en un manuscrito que los dioses se encargaron de convertir en un legado que se transforma en palimpsesto.

Sorprende y conmueve este tríptico por la fuerza no solo de lo que se dice, sino por aquello que al ser evocado es la reinvención de un mundo que adquiere una 
dimensión, una resonancia religiosa que lo convierte, como diría el mexicano Efraín Huerta, en "un territorio cercado". ${ }^{4}$

La sección "Poesía urgente para un mundo sin poesía” (pp. 157-170), Premio Internacional José María Valverde (Espańa 2013), de clara filiación brechtiana, es un registro de acontecimientos traumáticos, desconcertantes e insólitos de lo que es la escena posmoderna. Las demandas, las proclamas en soledad y desde el margen de los subalternos; las reconstrucciones de las identidades interferidas del sujeto migrante; el dibujo de ese lugar siempre sinuoso llamado patria; las marcas, otra vez del poder, o los rituales siniestros de ese machismo que niega a la mujer desde "la sevicia de un hombre/ la complicidad de todos los hombres/ la vasta crueldad de la condición masculina", en "Rosa Elvira Cely, empalada en Bogotá" (p. 163); mientras que la memoria y la historia se encargan de cobrar sus facturas a quienes en su momento creyeron que los fantasmas del pasado no volverían a hacerles guiños ni en la peor de sus pesadillas. Así sucede en el hermoso, estremecedor e irónico texto: "El sargento Terán recupera la vista" (pp. 164-65), en el que se cuenta la encrucijada que padece quien tuvo la "misión" de dispararle al Che cuando fue tomado prisionero en Bolivia; personaje que años después superara la ceguera física, más no la espiritual, gracias a un desquite de la historia y la vida. ¿La historia es una paradoja, un drama, una comedia mal contada o en fuga?

La poesía, tiene un diálogo con la historia que nunca ha sido de complicidad. Esto se revela en "Salvador Allende andando libre por las alamedas (1973-2013)". El sujeto poemático reconstruye, desde la idea del cronista poscolonial, lo que fue ese episodio atroz y vergonzoso de la historia contemporánea, no solo de un país como Chile sino de todo un continente y de un hemisferio. Crónica que nos recuerda que al poder y a los poderosos, todo aquello que tenga que ver con la posibilidad o amenaza de perder sus privilegios o intereses, siempre será razón y argumento para desempolvar sus viejas artimańas, sus tratados de Torquemada y Maquiavelo para ponerlos, en alianza con todos aquellos hijos e hijastros de las tinieblas, en vigencia. Este es un texto logrado por todo lo que tiene que ver respecto a lo que Seamus Heaney, llama "de la emoción a las palabras". 5 Sin duda, el origen y el fundamento de toda escritura poética. Como bien lo dice uno de los hablantes alternos al cerrar el texto:

La poesía cabalga marcando las huellas abiertas de la memoria y el verso, contaminado de mundo, reniega de la pureza y grita (p. 182).

\section{Frontera tatuada}

Mistica del tabernario es un texto polifónico. Un concierto que ensambla sabia e intensamente registros no solo de voces, sino de presencias, unas fantasmales y otras que adquieren un tono, un empaque entre religioso, místico y desacralizador.

4 Efraín Huerta, Transa poética (México: Era, 2014: 11).

5 Seamus Heaney, De la emoción a las palabras (Barcelona: Anagrama, 1996). 
Concierto que se cierra con la sección "Cuitas de amor por Colombia" (pp. 183203). Textos en los que Raúl Vallejo abraza, desde la memoria de la infancia, lo que es un lugar de frontera, un punto de la geografía que esa memoria resemantiza hasta ser parte de una experiencia de vida que la escritura trastoca en testimonio, revelación y canto de ese referente llamado Colombia; lugar que un adulto con responsabilidades asignadas por las circunstancias históricas y políticas o los azares de la vida, lo han llevado a habitar entre las gentes del pueblo del coronel Aureliano Buendía y de Ángela Vicario.

Los poemas de esta sección no están atravesados por el realismo mágico garciamarquiano. Sucede que lo mágico se desprende de la condición de los personajes y las situaciones que viven de manera particular cada una de esas criaturas que transitan por estas páginas como el mismo García Márquez; Eloy Alfaro, el general que lideró la Revolución liberal de 1895 en Ecuador; la mujer colombiana, su estado de gracia y de resistencia en un medio hosco y violento en el que su belleza es un elemento perturbador; Juan Montalvo y un episodio escamoteado de su exilio, de su pasado; la casa en la que habitaron los personajes inventados por el romántico Jorge Isaac; el cantante ecuatoriano Julio Jaramillo, interpretando los versos de su tocayo, el poeta J. Flórez; la sombra del modernista José Asunción Silva fundida con la de quien lo esculpió en bronce, Jorge Olave, en un destino de convergencias. Registro y revisión implacable del archivo de la historia de ese país del que el cronista, autor de este concierto de sombras y voces, debe, como dice el tango, dar la media vuelta y retornar a su lugar de origen.

Un lugar, una taberna o un cuerpo que para el poeta es la consumación de todos los lugares y cuerpos (Macondo, Madrid, Chapinero Bajo o Claudia) posibles e imaginables, cifrados en la reinvención de lo que las palabras y el lenguaje le han permitido fraguar y dar forma en Mistica del tabernario. Un orbe o códice que se reinventa a sí mismo, y en el que, como se anota en el colofón de un ensayo que

postula las claves de las que se nutre y contamina la poética de este concierto plural: "La poesía,/ bosque de sueños invadido/ por los espectros de la realidad".

Un bosque, habrá que agregar, en llamas, que por igual nos quema y purifica a todo aquel que se decida atravesarlo sin pensar si mañana será salvo o no. 